\title{
AS CORRIDAS DE RUA
}

De acordo com Salgado e Chacon-Mikahil (2006), as corridas de rua são definidas, conforme classificação da Associação Internacional das Federações de Atletismo (IAAF), como provas disputadas em circuitos de rua, avenidas e estradas com distâncias oficiais que variam entre 5 e 100 quilômetros.

Até meados da década de 1970, eram vistas exclusivamente como modo de preparação e competição para corredores profissionais de alta performance, porém esse panorama se alterou com o jogging boom nos Estados Unidos, que foi a popularização de uma metodologia de treinos para reabilitação cardiovascular elaborada pelo médico americano Kenneth H. Cooper, criador do Teste de Cooper. O grande sucesso de seu programa de condicionamento físico para militares norte-americanos passou a atrelar seu nome a um sinônimo de corrida e qualidade de vida (SALGADO; CHACON-MIKAHIL, 2006).

Os últimos anos vêm sendo marcados por uma crescente preocupação da população com hábitos de vida mais saudáveis. Isso culminou em um aumento de $287 \%$ no número de eventos de corrida de rua (Figura 1) e um aumento de 395\% no número de participantes (Figura 2) em São Paulo entre 2004 e 2015, como se pode ver nos gráficos a seguir. 

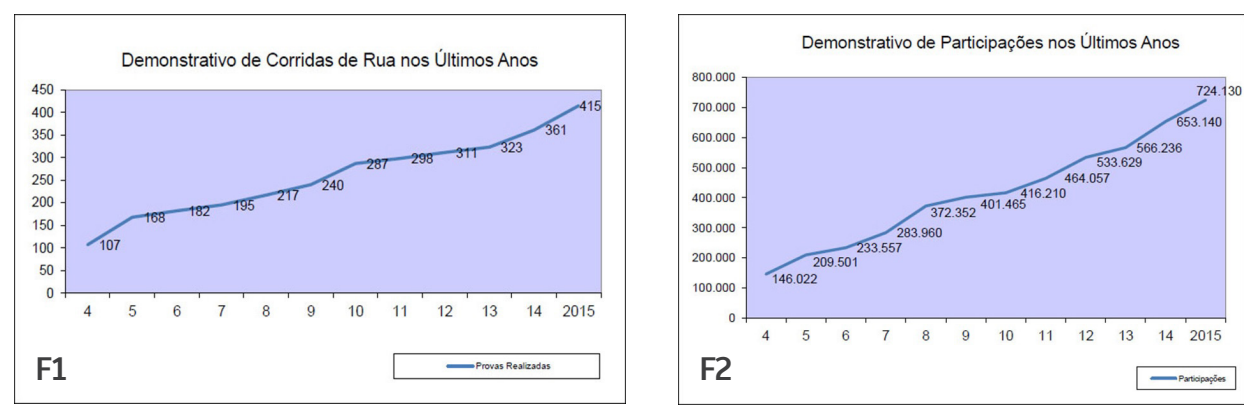

Figura 1 - Demonstrativo de eventos de corridas de rua entre 2004 e 2015. Fonte: FPA, 2015.

Figura 2 - Demonstrativo de participações em corridas de rua entre 2004 e 2015. Fonte: FPA, 2015.

Esse crescimento substancial ao longo dos anos tem ocorrido principalmente pelo fato de a corrida de rua ser um esporte considerado democrático e não requerer altos investimentos, como afirmam Ziliotto et al. (2015, p. 1):

Parte deste aumento dos praticantes de corrida se dá por conta de ser um esporte com grande facilidade de iniciação, pois não é preciso de muito investimento para poder começar a praticar, além de poder ser praticado em qualquer lugar e a qualquer hora do dia.

\subsection{Corridas convencionais e corridas imersivas}

Oliveira (2010) apresenta em sua pesquisa uma categorização feita pelo treinador entrevistado Leonardo Ribas, em que divide as corridas de rua em dois grandes grupos: as corridas convencionais e as corridas fashion:

As corridas convencionais são populares, geralmente estão vinculadas aos valores mais tradicionais da corrida. Nelas, a maior parte dos corredores pertence às classes sociais mais baixas e há uma maior participação de corredores de nível mais alto. Os corredores entrevistados afirmam que essas corridas são para "corredores de verdade" ou para os "profissionais". As corridas fashion são as corridas mais elitizadas do ponto 
de vista econômico. Nelas as inscrições têm valores mais altos que nas convencionais, a produção é mais elaborada e envolvem "só os que podem", alguns "corredores de fim-desemana", "bombadinhos", "patricinhas e mauricinhos”, um fato "lamentável" na visão dos corredores pesquisados (OLIVEIRA, 2010, p. 27-28).

Vale ressaltar que essa não é uma classificação científica das corridas de rua, mas é importante como norte desta pesquisa que têm como foco principal o estudo do que é colocado como corrida fashion devido ao alto nível de produção das peças de interação com o público, da temática imersiva proposta - que tem como intuito atrair maior número de corredores amadores -, da divulgação e dos elementos sinestésicos que a envolvem. Porém, como forma de estabelecer uma nova nomenclatura que se adeque a esse novo campo que será estudado, e para que essa classificação contemple satisfatoriamente os aspectos físicos e simbólicos desse novo gênero, as corridas fashion serão tratadas aqui como corridas imersivas.

As corridas imersivas são aquelas com alto grau de produção audiovisual e cenográfica, com temática bem definida e atrelada à divulgação de produtos, serviços e/ou eventos a ser comunicados aos corredores por grandes marcas, como histórias e personagens de quadrinhos, filmes, músicas, entre outros, e em horários e locais que ressaltem essas características, como corridas noturnas ou corridas atreladas a pontos turísticos. Esse universo é construído de modo imersivo por meio da direção de arte dos elementos interativos e sinestésicos disponíveis ao público durante o evento, que são capazes de despertar emoções positivas e criam relações afetivas com os corredores. Como forma de diferenciação, se as corridas convencionais têm como premissa enaltecer os valores mais tradicionais - o ato de correr e melhorar o desempenho -, as corridas imersivas apresentam uma nova proposta: elevar a experiência de vivenciar o ambiente e a temática do evento com as emoções que foram construídas ao patamar principal de atenção dos participantes, motivando-os a interagir com as peças cenográficas construídas pelos organizadores e com as marcas divulgadas, deixando os valores tradicionais, muitas vezes, em segundo plano.

McGonigal (2012) descreve os ambientes imersivos dos videogames, dando a eles o nome de ambientes épicos, espaços de grande escala construídos 
para provocar um profundo sentimento de admiração e encantamento nas pessoas. Assim, pode-se traçar um paralelo entre os ambientes épicos dos videogames e os ambientes das corridas imersivas. Ambos possuem objetivos semelhantes: criar um espaço de envolvimento, inspiração e cooperação para os usuários, de maneira que isso possa despertar emoções positivas e um caráter motivacional interligado à temática do evento.

De acordo com McGonigal (2012), nossa realidade já não nos proporciona atividades que tragam momentos de satisfação pessoal e prazer intensos com a frequência que gostaríamos, por conta da rotina diária do ser humano moderno. Assim, buscamos constantemente ambientes épicos como forma de potencializar nossas habilidades e receber recompensas que a realidade cotidiana não nos oferece constantemente.

As corridas de rua imersivas constroem ambientes épicos que procuram gerar momentos de fiero, conceito assim explicado por McGonigal:

Fiero é uma palavra italiana para "orgulho", é o que sentimos depois de triunfarmos sobre a adversidade. Só o conhecemos quando sentimos - e quando vemos. Isso porque quase todos nós expressamos o fiero exatamente da mesma forma: jogando os braços por sobre a cabeça e gritando. Os cientistas revelaram recentemente que o fiero é um dos estágios neuroquímicos mais poderosos que podemos experimentar (MCGONIGAL, 2012, p. 42).

Com isso, quanto mais desafiadores forem os obstáculos, quanto mais envolvente for a atmosfera do evento, mais intenso será o momento de fiero do indivíduo. Isso está ligado à construção de um ambiente épico imersivo e de objetivos e metas claros propostos pelos organizadores, além de recompensas satisfatórias para os participantes, algo que é encontrado em sua essência nas corridas de rua imersivas.

\subsection{As corridas de rua e o branded content}

Magalhães (2008 apud RIBEIRO, 2009, p. 15) demonstra a importância dos eventos como ferramenta de consolidação da imagem da marca perante seu público ao afirmar que 
o evento abre caminho para uma comunicação mais seletiva e aprimorada aos padrões atuais, trazendo versatilidade, inovação e descobrimento. Possui ainda a característica de aproximar as pessoas, promover o diálogo, mexer com as emoções, gerar sentimentos, e marcar presença. É considerado um dos mais ricos recursos de comunicação.

Para contemplar mais momentos de fiero, as corridas de rua foram se modificando e se adaptando aos meios e aos diferentes públicos participantes. De acordo com Dallari (2009, p. 16), as corridas de rua são um fenômeno sociocultural contemporâneo.

Cabe então estudar a corrida de rua como forma de expressão da sociedade nos dias de hoje, marcada por uma multiplicidade de valores e de hábitos, por transformações drásticas e rápidas, que se vale do apoio intensivo da tecnologia, sobretudo para a disseminação de informações e para deslocamentos, como fenômeno sócio-cultural. Compreender as corridas contribui para a compreensão do nosso tempo.

A construção desse fenômeno sociocultural passa diretamente pela união de marcas que ditam valores culturais com seu público consumidor. Nesse meio, temos o surgimento de uma ferramenta que visa potencializar essa relação, relacionando conteúdo de marca e valores emocionais: o branded content.

O novo cenário publicitário, que utiliza as mais variadas formas para se comunicar e interagir com os consumidores, tornou a mídia tradicional algo maçante e pouco atrativo, cabendo aos publicitários encontrar novas alternativas para comunicar conteúdos e valores de marca ao público. Assim, como afirma Achutti (2010, p. 8), o branded content

é uma destas estratégias que nasceram com o objetivo de ir além da comunicação persuasiva. É uma forma de fazer com que ao se relacionar com um conteúdo produzido pela própria marca, o consumidor receba algo em troca, seja na forma de conhecimento, entretenimento ou informação. 
Na prática, segundo Alves (2016, p. 2), branded content "são iniciativas que mesclam entretenimento, informação e publicidade, com o objetivo de criar vínculos emocionais e estreitar a relação entre o consumidor e a marca".

A utilização de branded content nas corridas imersivas propõe maior engajamento do público com a marca, haja vista que a atmosfera criada em torno do ambiente da corrida pressupõe aspectos emocionais e constrói experiências positivas com um público consumidor em potencial. De acordo com Alves (2016, p. 7),

as iniciativas de Branded Content podem ser bastante abrangentes, englobando os mais variados formatos, como comerciais, filmes, séries, sons, músicas, publicações, redes sociais, jogos, aplicativos, eventos, e utilizando diferentes e/ou múltiplos suportes, como meios de comunicação de massa, internet, dispositivos móveis e espaço urbano, para gerar conteúdo associado às marcas.

Portanto, marcas que atrelam sua imagem e produtos a corridas de rua buscam construir um vínculo emocional forte com seus consumidores, visando partilhar dos mesmos valores que eles, os de uma vida de hábitos saudáveis, atrelada à ideia de movimento própria dos praticantes de corrida de rua. Sob outra ótica, as corridas imersivas também reforçam uma imagem que é construída junto com o ambiente épico da corrida, aflorando valores afetivos muito próximos dos corredores e que poderão ser lembrados mais fortemente em uma eventual compra do produto ou serviço.

Norman (2012, p. 81) completa dizendo que "as marcas têm tudo a ver com emoções. E emoções têm tudo a ver com julgamento. As marcas são significantes de nossas respostas emocionais, que é o motivo pelo qual elas são tão importantes no mundo comercial". 